\title{
Employing the Social Media and the Mobile Phones (GSM) in the Campaign Against Open Defecation in South-East Nigeria
}

\author{
Peter N. Nwokolo ${ }^{1} \&$ Marycynthia A. Nwokolo ${ }^{2}$ \\ ${ }^{1}$ Department of Mass Communication, University of Nigeria, Nsukka, Enugu State, Nigeria \\ ${ }^{2}$ Department of Foreign Languages and Literature, University of Nigeria, Nsukka, Enugu State, Nigeria \\ Correspondence: Peter N. Nwokolo, Department of Mass Communication, University of Nigeria, Nsukka, Enugu \\ state, Nigeria
}

$\begin{array}{lc}\text { Received: January 3, } 2021 & \text { Accepted: February 18, } 2021 \quad \text { Online Published: February 25, } 2021 \\ \text { doi:10.5539/gjhs.v13n4p38 } & \text { URL: https://doi.org/10.5539/gjhs.v13n4p38 }\end{array}$

\begin{abstract}
This exploratory study investigated the viability of using the social media and mobile phone (GSM) as public relations social marketing tool in the campaign against open defecation in South-East Nigeria. It argues that the greater percentage of the public could be reached with the campaign if approached through the social media networks and GSM such as the Facebook, mobile telephone, etc., than the traditional media of newspapers, radio and television that have not yielded much in the envisaged awareness and attitudinal change results. From a survey sample of 385 respondents drawn from three sampled states of Enugu, Anambra and Abia, using the simple random, convenience and purposive sampling techniques, the results suggest, among others, that the social media and the GSM could be more efficacious in prosecuting the campaign against open defecation given the fast growing social media literacy and GSM use among the population especially the youths. It recommends that given the increasing number of the segment of the society especially the youths that use the Social Media and GSM the South-East governments could conduct basic or pilot study so as to leverage on this accessibility aspect of the media for a more effective campaign to end open defecation in South-East Nigeria.
\end{abstract}

Keywords: viability, social marketing, social media, media literacy, southeast, Nigeria, exploratory, accessibility, facebook, mobile phones, newspapers, sampling, open defecation, toilet, campaign

\section{Introduction and Literature Review}

According to Igomu (2019), the 2018 NORM Report showed that 47 million Nigerians did not have toilet and another 75 million used unimproved toilet facilities. Another study jointly carried out by the National Bureau of Statistics, Federal Ministry of Water Resources and UNICEF disclosed that Nigeria loses N455 billion (US\$1.36) annually due to poor sanitation. These losses, they concluded, constituted one percent of Nigerian's GPD and are responsible for premature deaths and diseases such as cholera, typhoid, trachoma, diarrhea, stomach upset, hepatitis, among others. It is sad to observe that many diseases ravage Africa because of ignorance and unbridled skepticism. While many still doubt the existence of COVID 19 known as Coronavirus others do not yet understand the health dangers associated with open defecation.

In his work titled "Hepatitis: Deadlier than Aids, Experts regret lack of awareness, As Nigeria marks world day of Hepatitis..." Ayobami (2017, P.15) regretted that many people are still unaware that open defecation which a large segment of the population practice with relish was among the major reasons they suffer from such infectious illnesses as Hepatitis, skin rashes, etc.

As warned by (WHO, 2017) there is Worldwide spread of Hepatitis B and it is currently a key global public health concern that needs immediate attention and one sure way to contain the danger in to avoid open defecation and improve environmental hygiene.

In this publication titled "Public places turn public toilets ... As open defecation thrives in Nigeria" Igomu (2019, P.18) observed that with open defecation becoming an enshrined culture, the country, according to the United Nations Children Funds (UNICEF), would be spending about N95 billion annually if open defecation is to be eliminated.

Similarly, Adepoju (2019) in his article captioned "Why Nigeria's campaign to end open defecation is failing" opined that Nigeria needs an estimated 959billion. 
Nigerian Naira $(\$ 2.7)$ to end open defecation by 2025 , noting that presently only 11 of Nigeria's 774 local government areas have been certified free from open defecation as the federal government is yet to release its share of funding for the campaign objective.

He noted that besides significant health risks linked to death from contagious diseases lack of toilets is also a risk factor for violence against women and girls who, for example, may be forced to leave home in the dark to find somewhere to defecate. Given the capital intensive nature of providing toilets and the economic crunch arising from the COVID 19 pandemic, it is doubtful if Nigeria, including the South-East, can beat the 2025 timeline for ending open defecation. As observed by Ugwuanyi (2020, P.5). The country's economy was thrown into shambles and both government and individual are yet to recover from the devastation caused by the pandemic. Right now, he added, many families are finding it extremely difficult to have one or two square meals in a day. Thus the 2025 deadline to end open defecation in Nigeria needs substantial economic support and sustained campaign to succeed.

Earlier, some Global health agencies had stressed that Nigeria needed to lunch a serious campaign against open defecation to attain Goal 6 of the United Nations Sustainable Development Goals 2030.

For the past three years, radio Nigeria Enugu that covers the entire SouthEast, particularly its branch in Nsukka, (Voice FM) has been in the forefront of this campaign towards eradiating open defection. The main concern of this paper is that one cannot continue to apply the same solution to a problem that persists and yet expect a different result. Some active users of Social Networking Sites among South-East states residents have wondered why the social media and the mobile phones, despite empirical evidence of their efficacy in campaigns against many health challenges, have not been employed in this all important effort toward awareness and attitudinal change campaigns. As observed by Evans-Cowley (2010), online social networks, particularly the Facebook, have demonstrated the potential to become a more successful tool for information dissemination and planning processes. Thus there is currently a global recognition of the potency of the digital social media and GSM in transforming the various parts of the society especially as it affects public health communication and delivery. Digital media which include the Internet (accessed through computer and mobile platform), digital satellite broadcasting (through pay- TV), digital terrestrial television (through embryonic free-to-air TV), and mobile television (using DVB-H), etc. (Ayedum-Aluma, 2017), have proved from various empirical studies to hold significant promise in addressing major public health challenges confronting the African continent. Such optimism, according to Neuhauser and Kreps, (2010; USA1D, 2008; Waters 2011) is based on the increasing levels of internet penetration into the nooks and crannies of the society in addition to the intrinsic characteristics of the social media that include: "Interactivity, genuine dialogue, speed, multimodality, user-generated content, mass customization, horizontal communication and multi-directionality of information". Thus this paper examines the promise of using the digital media as the social marketing campaign tool to eradicate open defecation and its health hazards in South-East Nigeria. For as observed by McNab (2009) "Social media offers timely and credible health information critical for improving public health outcomes quickly and directly". In their study of the effectiveness of mobile phones as a digital platform for health communication, De Tolly and Benjamin (2011) concluded that the GSM and the Social Media supply information and enable people to interact with that information, and also deliver services that strengthen health systems. They maintained that mobile telephony as a digital game-changing technological device, has the uncommon ability to reach more people with health information, facilitate interactivity and promote confidentiality of use. In a similar vein, Salmon and Arkins (2003) in their work "Using media campaigns for health promotion", suggested that digital media platforms have now become an indispensable tool for health literacy and for overall improvement of health outcomes.

Though we recognize that the social media and the GSM also have their shortcomings in terms of social exclusion due to cost, limited access to mobile phones, content restriction and limited personalization of health information (De Tolly \& Benjamin, 2011), in addition to being an easy source of misinformation because of information agility and social connectivity, yet available empirical studies such as those of Evans-Cowley (2010), Fayoyin (2017), etc. suggest that the strengths of the digital social media and GSM in health information delivery outweigh the weaknesses. For instance, in the case of Ebola outbreak in Nigeria in 2014, which discovery caused a global scare due to the populous nature of the country and the fear of the catastrophic consequences of a full-blown epidemic for the global community (WHO, 2015), many commentators rightly attributed the success in controlling the highly contagious hemorrhagic fever principally to the impact of social media and mobile phones. At that time, Nigeria was said to have over 130 million mobile phone users, 67 million internet subscribers that played a vital role in the information dissemination (Ayedum-Aluma, 2017). In an article published in a high profile British medical journal titled "How Twitter may have helped Nigeria contain Ebola", Carter (2014) opined that targeted mobile phones and social media campaigns in Nigeria helped to disseminate accurate information about the disease and to correct hoax messaging. And for Wire (2014) health workers also used a combination of Android 
Apps, Facebook, Twitter and Goggle Trends to identify topics of interest on the issue of Ebola and to communicate such to the public. This, he maintained, provided real-time information on the causes of Ebola, its spread, diagnosis and treatment. According to West, (2014) countless SMS platforms were employed in circulating messages on the signs and symptoms of the virus. For instance, this writer happened to be in the village when at about 4.30 am an illiterate woman came and woke me up. She narrated how relations at Abuja called to alert her on the Ebola disease and advised her to drink salt solution and eat bitter-cola. The woman went from house to house alerting everybody. Similar SMS messages were received in many rural communities from relations and friends living in different parts of the country, some with the unintended untoward consequences especially where some diabetic patients who, maybe, took an overdose of the supposedly preventive salt solution, died as a result. Thus, with immense coordinated deployment of the digital media, particularly the mobile phone, only 20 people reportedly died in Nigeria from Ebola compared to nearly 8,000 and 7,700 in Sierra Leone and Liberia respectively (West, 2014).

We have gone at length in the above review of literature to show why government at all levels in Nigeria should now much more than before, begin to factor the digital media into its health polices in view of the potential powers of the innovative technology.

This is critical given the series of campaigns that have been carried out over the years through the conventional media such as the radio, television, newspapers to the exclusion of the digital media, designed to mobilize against open defecation in South-East all to no avail and yet more campaigns are organized.

The scenario reminds one of a bunch of stage clowns who Achebe (1983) regretted bump their heads into the same heavy obstacles again and again because they are too stupid to remember what hit them only a short while ago.

For instance, Radio Nigeria, Voice FM referred to above has continued to carry out campaign against open defecation for at least, three years running now. This is done both in English and Igbo languages apparently in an attempt to reach both the literate and non-literate ones on the health hazards associated with open defecation. Also, the $19^{\text {th }}$ day of November every year, known as the World Toilet Day (WTD) is an official United Nations International observance day which has become a global campaign phenomenon designed under Sustainable Development Goal 6 to achieve sanitation for all and end open defecation. Founded by a philanthropist from Singapore Jack Sim, the World Toilet Organization (WTO) has been campaigning since November 2001, through the conventional media (Vanguard Thursday, August 8, 2011 p.35).

Recently, the print media were awash with reports on a new campaign to end open defecation in Nigeria by 2025. Titled "Clean Nigeria, Use the Toilet Campaign" the thrust of the mobilization launched by UNICEF in Calabar at a dialogue and partnership meeting with the media was that by the first of October 2019, Nigeria would replace India as the "World capital of open defecation with over $47 \mathrm{~m}$ person" According to the (Vanguard newspaper report August 8, 2019, p.35), one in every four Nigerians (24.4 percent) defecates in the open. It added that "the South-West zone came second with 28.0 percent followed by the SouthEast, (our study population) with 22.4. In view of the seriousness of the situation, the Chief Scientific Officer, Federal Ministry of Water resources Mrs. Yeme Akpa disclosed that the Federal Government has "approved the sum of N10 billion, to be released annually till 2025 to sustain the campaign against the practice and for the campaign to be successful." However, what is to be borne in mind is that a phenomenistic approach to make a campaign successful requires that in addition to other critical elements, the appropriate media must be deployed to help navigate the mediating factors both social and psychological that hamper success.

As asserted by Hyman and Sheatsly (1947), there are some psychological factors that make information campaign to fail. These, they stated, included: natural predisposition which reveals that certain proportion of the population remain consistently unfamiliar with any particular event, making them chronic "know-nothings", lack of interest, selective exposure due to different personality factors and motivations, congeniality of information with prior attitudes, selective interpretation and above all, the fact that information does not necessarily change attitude. But by its intrinsic characteristics, social media and mobile phones can break through most of the above barriers, hence the need for platform shift in the campaign against open defecation. These include such attributes of intimacy, specificity and dialogue, cost-effectiveness compared to television, print or radio, nimbleness, measurement, newness, a quality that attracts the digital media to the audience and, active participation in addition to a promising future.

It is for the above qualities that we sought to ascertain the workability of the digital media considering the series of failed previous campaigns against open defecation such as the one launched in 2018 by the Federal Government. (NAN, 2018), the one launched by UNICEF (Vanguard, August 8, 2019, p.35) and that which has been running in the Radio Nigeria for upwards of three years now yet, no observed impact. All these campaigns have been in 
operation in South -East, using the conventional media.

South-East is one of the six geopolitical zones in Nigeria. The zone consists of Abia, Anambra, Ebonyi, Enugu and Imo States.

It is on the above geopolitical zone, South-East that the survey on the workability of the digital media (as a tool in the Social Marketing public relations model, described by Nwosu and Uffoh (2005) as a strategy of marketing that is used for marketing or selling not-for-profit development ideas to specified target individuals or groups) was administered to ascertain the suitability in the campaign against the practice of open defecation.

\subsection{Research Problem}

The social media and the mobile phone could, to all intents and purposes, be regarded as a gargantuan revolution in social communication after the conventional media namely, newspapers, radio and television had existed. These traditional media have been used as tools in social marketing campaigns, most times, with limited success due perhaps to their inherent weaknesses. As for the digital media such as the Face-book, WhatsApp, mobile telephony etc., which are entirely new inventions, there is some confusion in public opinion about their capability as a social marketing tool to drive media campaigns against open defecation and the concomitant contagious diseases that ravage the Nigerian society. The problem of this exploratory survey therefore is to investigate the workability of the social media and the smart phone as an effective social marketing tool in the campaign to eradicate open defecation in South-East Nigeria so as to enable us make informed recommendations.

\subsection{Objectives of the Study}

The overall aim of this research is to investigate the possibility of employing the social media and mobile phones as Social Marketing tool in the campaign to eradicate open defecation in South-East State of Nigeria Specifically, the objectives of this study are:

i. To investigate the suitability of applying the social media and the mobile phones tool in the PR Social Marketing campaign to eradicate open defecation in South-East.

ii. To identify and assess the aspects of the social media and the GSM that make them relevant as a tool in the Social Marketing campaign to end open defecation in South-East States of Nigeria

iii. Determine how these aspects of the social media and the mobile phone can best serve as tools for enlightenment campaign to stop open defecation in South-East States.

iv. To interrogate the use of social media and the mobile as, a comprehensive enlightenment strategy for winning the campaign against open defecation by advocating the use of toilets in South-East States, Nigeria.

\subsection{Research Questions}

Consequently, the following research questions will guide the study.

i. Can the social media and the mobile phone be possibly employed as a social marketing public enlightenment tool or strategy for eradicating open defecation in South -East Nigeria?

ii. Can the PR social marketing model, using the social media and the GSM tools serve as an operational model for the application of public relations techniques and strategies in the promotion of "Clean Nigeria, Use the Toilet Campaign?"

iii. Can the PR social marketing model, using the social media and the GSM technology help us come up with a more comprehensive public relations strategy for winning the campaign against open defection in South-East Nigeria?

iv. Must all the components of PR Social Marketing model, using the social media and the mobile phone, be used together as a package in order to win the public enlightenment and attitudinal change campaign to end open defecation?

\subsection{Theoretical Framework}

The Agenda Setting theory guided this study. The history of Agenda Setting theory dates back to 1968 US Presidential election. In the theory, McCombs and Shaw (1972) propounded that "media emphasis on an event influences the audience to see the event as important." The use of the word "influence" is an acceptance that the media do not constitute necessary and sufficient causes of audience effect though some studies have demonstrated that changes in behaviour can arise from the nature of media coverage (Klapper, 1960; Fayoyin, 2017). Elaborating their Agenda-Setting theory further, McCombs and Shaw (1972) posited that most of what people know come to them "second" or "third" hand from the mass media or other people and concluded that the media 
are the major primary source of national political information. According to the duo, "while the mass media may have little influence on the direction of intensity of attitudes, it is hypothesized that the mass media set agenda for each political campaign". The mass media provide the best and only easily available approximation of everchanging political realities. Though the political world is reproduced imperfectly by individual news media, yet the results from the study suggest that voters tend to share the media's composite definition of what is important, suggesting an agenda setting function of the mass media.

From time immemorial, the various aspects of the media, (whether it was the town-crier in the traditional African society or the conventional media that came with colonialism), have been used as a source of information, education and entertainment. The media had been instrumental to the achievement of Nigeria's independence without bloodshed, in wresting power from the military and in restoring Nigeria to liberal democracy since 1999.

It is in view of the power of the media to sensitize the people to urgent issues in the society that this study examined, the view, opinions, and perceptions of active users of the GSM and the social media networks and public relations experts regarding the utility or efficacy of the social media and the mobile phones as a new media platform, in the campaign to eradicate open defecation within the South East states. In agricultural activities, the mobile phone had been used in sharing important information between the rural farmers and government agencies and in the times of the Ebola epidemics, health officials disseminated urgent medical information through the Facebook. And in the prevalent COVID-19 pandemic, the Facebook, mobile phones and other branches of the digital media have been of great service to the government and the people in fighting the pandemic through information sharing on the need for regular hand washing, social distancing and general hygiene for good health.

It is on the above platform that this study tried to ascertain from experienced users of the social media and the mobile phones, whether the network can be usefully deployed, in addition to the conventional and traditional media electrically in the campaign to end open defection among the residents of South-East States of Nigeria. This will complement the "Clean Nigeria, Use the Toilet Campaign" as lunched by President Buhari through the analogue, so far, unproductive traditional media in November, 2019.

\section{Methodology}

The study adopted the survey method which as posited by Odo (1992, p42), "deals with the practical application of the already standardized theories available in social and behavioural sciences". Similarly, Osuala, (1991, p181) observed that "survey research focuses on people, the vital facts of people and their beliefs, opinions, attitudes, motivation and behaviours" e.g. open defecation. Thus this form of research is appropriate to this study.

For data collection, both primary and secondary sources were used. The primary sources included questionnaire administration and personal oral interviews designed to complement the data available from the questionnaire.

The secondary sources included newspapers, books, journals, government documents, etc. relevant to the study focus.

\subsection{Population of the Study}

The universe of the study includes all the residents of the five South-East of Abia, Anambra, Ebonyi, Enugu, and Imo

According to the National Population Commission (2006), the population of South-East Nigeria is 16,395,555. But because the figure has become statistically obsolete, the researcher deemed it necessary to adopt the population formula suggested by Owuamalam $(2020$, p.107) to arrive at a more current population figure below:

$$
\mathrm{PP}=\mathrm{GP} \times \mathrm{P} 1 \times \mathrm{T}
$$

Where PP $=$ Projected Population

$\mathrm{GP}=$ Given population at last Census

$\mathrm{P} 1=$ Population increase index (2.28)

$\mathrm{T}=$ Period between last Census and the year of Study

To compute the $\mathrm{PP}=$

$\mathrm{GP}=16,395,555$

$\mathrm{P} 1=2.28 \%(0.0228(0.023 \%)$

$\mathrm{T}=2019-2006=13$

$\mathrm{PP}=16,395,55+0.023 \times 13=490,2271$. 
$\therefore$ the projected population of South-East Nigeria as at the time of this study was 49,022,71.

It is from the population figure that we drew the respondents comprising active users of the social media, public relations officers knowledgeable in media campaign and environmental health officers whose population size was not definite.

\subsection{Sample Size}

In determining the sample size of the study, we adopted the method enunciated by Camrey and Lee (1992) as cited in Wimmer and Dominick (2003) thus: "For multivariate studies: $50=$ very poor; $100=$ poor; $200=$ fair; $300=$ good...."

The sample size of the study is 385 respondents.

It was from the respondents that expert opinions and views were elicited through the questionnaire instrument administered on them that were sampled from the states mentioned above. Going by Wimmer and Dominick's (2003) assertion, a sample size of 385 is good in a multivariate study of this nature.

\subsection{Sampling Technique}

The multi-stage sampling technique was adopted in carrying out the study to ensure proper representation (Chukwuma, 2002).

First, the simple random sampling approach was employed to draw three states of Anambra, Enugu and Imo out of the five states that make up South-East Nigeria.

Next, the state capital of each of the three states was purposively selected because of the high literacy level of the residents. Also, the capitals have a good number of people who make use of the internet, mobile phone and the social media networking sites for information sourcing.

In each of the state capitals are government secretariats where the different ministries are situated and people and government workers mill around. The convenience and purposive sampling techniques were used to select the readily available respondents that possess the requisite knowledge of social media and the GSM use, public relations and environmental health officers. They were the ones that were given copies of the questionnaire to fill.

The researcher chose Tuesday mornings when workers who travelled during weekends had returned and this helped in the high rate of return of the questionnaire which were earlier tested for validity and reliability.

\section{Data Presentation and Analysis}

Here the quantitative data generated through the questionnaire were analysed and presented in tables and percentages.

Out of the 385 copies of the questionnaire copies distributed, nine (9) were rejected as they were not properly filled, while some were not returned, leaving us with 376 respondents figures to work with.

Table 1. Sex distribution of Respondents

\begin{tabular}{lcc}
\hline Sex & Frequency & Percentage (\%) \\
\hline Male & 209 & $55.6 \%$ \\
Female & 167 & $44.4 \%$ \\
Total & 376 & $100 \%$ \\
\hline
\end{tabular}

Source: 2019 field work.

The above Table 1 shows the sex distribution of respondents. 
Table 2. Determination of educational attainment of respondents

\begin{tabular}{lll}
\hline Educational Attainment & Frequency & Percentage (\%) \\
\hline First School Leaving Certificate & 52 & $13.8 \%$ \\
Senior School Certificate & 111 & $29.5 \%$ \\
NCE/OND & 59 & $15.7 \%$ \\
HND/B.SC & 145 & $38.6 \%$ \\
M.SC/Ph.D & 09 & $2.4 \%$ \\
Total & 376 & $100 \%$ \\
\hline
\end{tabular}

Source: 2019 field work.

The above Table 2 shows the qualifications or educational attainment of respondents.

\subsection{Research Objective Number One}

To investigate suitability of social media platform and the GSM as effective PR Social Marketing Public enlightenment campaign tool for eradicating open defection in South-East Nigeria.

Table 3. Determination of the suitability of the social media networks and the mobile phones as an effective social marketing tool for campaign against open defecation in South-East Nigeria

\begin{tabular}{lcc}
\hline Responses from respondents & Frequency & Percentage (\%) \\
\hline Those who answered YES & 322 & $86 \%$ \\
Those who answered NO & 29 & $8 \%$ \\
Those who answered they did not know & 25 & $7 \%$ \\
Total & 376 & $100 \%$ \\
\hline
\end{tabular}

Source: 2019 field work.

The above Table 3 speaks for research objective one (1)

\subsection{Research Objective Number Two}

Assessing the aspect of the social media and the GSM that make them relevant as a tool in the Social Marketing Campaign to end open defecation in South-East.

Table 4. Can the PR Social Media Marketing Model, using the social media and the GSM network serve as operational model for the application of public relations techniques to promote the "Clean Nigeria, Use the Toilet Campaign?"

\begin{tabular}{lcc}
\hline Responses from respondents & Frequency & Percentage (\%) \\
\hline Those who answered YES & 178 & $47.3 \%$ \\
Those who answered NO & 119 & $32 \%$ \\
Those who answered they did not know & 79 & $21 \%$ \\
Total & 376 & $100 \%$ \\
\hline
\end{tabular}

Source: 2019 field work.

The above Table 4 explains the respondent's views on research objective number two (2).

\subsection{Research Objective Number Three}

To interrogate the use of social media networks and the mobile phones as a comprehensive enlightenment strategy for winning the campaign to stop open defecation in South-East States 
Table 5. Can the PR social marketing approach, using the social media networks and the GSM help us come up with a more comprehensive public strategy for winning the campaign against open defecation in South-East Nigeria?

\begin{tabular}{lcc}
\hline Responses from respondents & Frequency & Percentage (\%) \\
\hline Those who answered YES & 149 & $39.6 \%$ \\
Those who answered NO & 98 & $26.06 \%$ \\
Those who were undecided & 129 & $34.3 \%$ \\
Total & 376 & $100 \%$ \\
\hline
\end{tabular}

Source: 2019 field work.

Table 5 narrates the result of the research objective number three.

\subsection{Research Objective Number Four}

To determine whether all the components of PR social marketing model employing the social media network and the GSM, must be used together as a package in order to win the enlightenment and attitudinal change to end open defecation?

Table 6. Must all the components of PR social marketing model, using the social media networks and the GSM be used simultaneously in order to win the public enlightenment and attitudinal change campaign to eradicate open defecation?

\begin{tabular}{lcc}
\hline Responses from respondents & Frequency & Percentage (\%) \\
\hline Those who gave affirmative answer & 191 & $51 \%$ \\
Those who answered NO & 120 & $32 \%$ \\
Those who were undecided & 65 & $17.3 \%$ \\
Total & 376 & $100 \%$ \\
\hline
\end{tabular}

Source: 2019 field work.

Table 6 above explains responses to research objective number four.

\section{Discussion on Findings}

The need to organize campaigns against open defecation was dictated by the fact that there appears to be a high degree of ignorance on the dangers and evil consequences of the practice on the health of the populace and therefore one of the major causes of the persistence of the habit. Old habit, they say, die hard! and people perish because of ignorance. Proper and convincing knowledge is what usually leads to behavioural change and a change in opinion will, other things being equal, lead to a corresponding change in attitude and behaviour. Apart from media reports, many people could not imagine that Nigeria shamefully ranked second to India among countries that defecate in the open fields, into the rivers, streams, gutters, etc. It becomes urgent that stakeholders in different fields of endeavour will, in addition to media campaigns, begin to strategise on how to encourage the use of toilet not only in the South-East, but Nigeria at large.

Response to research question number one shows that a reasonable percentage of the respondents precisely $86 \%$ answered in the affirmative regarding the capability of the social media and the mobile phone as tools in the PR Social Marketing public enlightenment campaign for the eradication of open defecation in South-East Nigeria. The affirmative response was based on the past effective performance of the social media and the mobile phone in health communication.

The second research question also showed that the responses obtained from the respondents suggest that PR Social Marketing, using the social media tool and the GSM, can serve as an operational model for the application of public relations strategies for eradicating open defecation and promoting the "Clean Nigeria, Use the Toilet Campaign" and other such campaigns with identical objectives among South-East states. For example, Table 4 above showed that as much as $47.3 \%$ of the respondents gave an affirmative answer to research question number two. This agrees with McNab's (2019) assertion that "more than any time in history, social media offer timely and 
credible health information, critical for improving public health outcomes quickly and directly". 'This may be due to the large number of subscribers complemented by the GSM that has more than any media gadget, reached the greatest number of people scattered both in the urban and rural country sides. For instance, as at June 2015, the country's regulator for the telecommunication industry, the Nigeria Communication Commission (NCC) put the number of subscribers in the country at 148,592,767, with GSM dominating with a massive 146,486,789 active subscribers ahead of CDMAI's 2,105,981 active subscribers. It also noted the rise in mobile internet subscription from $81,891,840$ as at January 2015 to over 88 million by the end of May, 2015 (Okonji, 2015). The social media and the GSM have become closer to the people even among ruralites who form about $70 \%$ of our population (Nwosu \& Uffioh, 2015).

On the question of developing public relations strategy, Table 6 shows that respondents strongly agree that PR Social Marketing Model and the GSM have been found a reliable vehicle for communicating and changing public attitude. As noted by Edeani (1993), public relations activities do influence the formation of public opinion and that there is a reciprocal relationship public relations and public opinion on the one hand and public opinion and attitude change on the other. As posited by Jefkins (1993) public relations, based on the transfer process, can enable an organization, be it government or otherwise, "convert four negative states into positive ones whereby hostility is converted into sympathy, prejudice into acceptance, apathy into interest and ignorance into knowledge." When the social media and the GSM are incorporated into Social Marketing, the opinion is that the campaign will be overwhelmingly successful being a comprehensive PR package.

The social media and the mobile phone, when combined with the social marketing strategies, can reach, according to the N-step flow theory, opinion leaders of the church, traditional institutions, schools and other social organizations with any message much more easily than the conventional media. Through the Facebook, GSM, WhatsApp, etc. the messages of the dangers of open defecation can get to the nooks and crannies of the society. Thus, while not suggesting that the conventional media should be discarded, we advocate that the social media and the mobile phones be given priority as a social marketing tool, based on the essential characteristics for a more effective delivery of the campaign messages as both the illiterate and non-illiterate, young and old, male and female are all implicated in the open defecation practice. A healthy nation is a wealthy nation and ditto SouthEast States.

\section{Conclusion}

Using the digital social media and the GSM as veritable tool for effective public enlightenment that should lead to a healthy behavioural attitude of using the toilet instead of engaging in open defecation is recommended. When the people embrace the practice in the idea being sold in the campaign, the prevalence of cholera, and other contagious diseases will be eradicated.

\section{Recommendations}

Based on the findings from the research objectives, the following recommendations below are made:

i. Government in South-East States should commission a basic research programme to explore the suitability and possible benefits of using the social media network and the GSM to educate their residents on the need to fight the diseases that go with open defecation by stopping the habit.

ii. Given the increasing number of active users of the social media networks and the GSM, it is suggested that the social marketing approach to public enlightenment be explored by the South-East governments so as to find ways of stimulating people's interest through the social media and the GSM. This may come by way of lunching their own campaign of "Clean South-East,

Use the Toilet Campaign" to complement the Federal Government's programme to end open defecation by 2025 .

One aspect of the social network that makes it a useful tool for the campaign against open defecation is its appeal to the youths; this can be leveraged on by government in this important campaign.

iii. Accessibility is an important aspect of the social media and the mobile phones which manifests in its ability to reach users both in the urban and the rural areas unlike the conventional media that are encumbered by mediating factors. The mobile phones are handy and available and had caught the fancy of majority of the people.

From our findings, it is suggested that all the components of the PR social marketing model, facilitated by the use of the social media networks and the GSM gadget be employed in the campaign against open defecation. For instance, the product to be sold which dwells on the dangers of open defecation should be sufficiently explained and made available at every available public space so as to attract and sustain public concern to the need to stop open defecation in South-East Nigeria. 


\section{Competing Interests Statement}

The authors declare that there are no competing or potential conflicts of interest.

\section{References}

Achebe, C. (1983). The trouble with Nigeria. Enugu: Fourth Dimension Publishers Co. Ltd.

Ayedum-Aluma, V. (2017). Digital media, new order? Emergent practices in the Nigerian media environment. ACSPN Book Series 2: Canada University Press, Concord Ontario, Canada.

Carter, M. (2014). How twitter may have helped Nigeria contain Ebola, BMJ, 369, 96946. https://doi.org/10.1136/bmj.g6946

De Tolly, K., \& Benjamin, F. (2011) Mobile phones: Opening new channels for health communication. In Waisbord, \& R. Obregon (Eds.), Handbook of global health communication. Oxford: Wiley-Blackwell. https://doi.org/10.1002/9781118241868.ch15

Edeani, D. (1993). Public relations, public opinion and attitude change. In A. O. Salu (Ed.), Public relations for local government in Nigeria, Lagos (p.109). Talkback Publishers Limited.

Hyman, \& Sheatsley. (1947). Some reasons why information campaigns fail. Public Opinion Quarterly, 11, 412-423. https://doi.org/10.1093/poq/11.3.412

Igomu, T. (2019, May 23). Public places turn public toilets.....As open defecation thrives in Nigeria. Daily Sun, p. 16

Jefkins, F. (1993). Planned press and public relations, Blackie, Edinburgh: Jefkins, M and Ambrosini with collier, N. (2007) Advanced Strategic management: A multi-perspective approach, 2nd edn, Palgrave Macmillan, Basinstroke.

Kottler, P., \& Lee, N. (2008), Social marketing: Influencing behaviours for good. Los Angeles: Sage Publications.

McNab, C. (2009). What social media offer to health professional and citizens? https://doi.org/10.2471/BLT.09.066712

Neuhauser, L, \& Kreps, G. L. (2010). E-health communication and behaviour change promise and performance. Social semiotics, 20(7), 24. https://doi.org/10.1080/10350330903438386

Nwosu, I., \& Uffoh, V. O. (2005). Environmental public relations management, principles, strategies, issues and cases. Enugu: Institute for Development Studies, University of Nigeria Enugu Campus.

Odo, O. (1999). Research in social and behavioural sciences (p.42). Enugu: XY2 Publishers.

Osuala, E. C. (1991). Introduction to research methodology (p.18). Onitsha: Africana-Fep Publishers.

Radio Nigeria, Voice FM 96.7 Nsukka a substation of the Federal Radio Corporation of Nigeria (FRCN).

Salmon, C. T., \& Arkins, C. (2003). Using media campaigns for health promotions. In T. L., Thompson, A. M. Dorsey, K. L. Miller, \& R. L. Parrots (eds), Handbook of health communication (pp. 449-472). Mahwah N.J: Lawrence Erlbaum Associates.

UNAIDS. (2011). Preventing HIV with social and mobile phones. Retrieved from http:www.unaids.org/en/resources/presscentre/featurestories /2011/may/20110502sm

UNICEF. (2019). Nigeria to become world capital of open defecation with over $47 \mathrm{~m}$ persons. Vanguard, p.35.

UNICEF. (2019, August 7). Nigeria ranks second in open defecation. NAN, p35.

USAID. (2008). New media and international development: A resource guide for Europe and Eurasia. Washington; USAID.

Waters, J. K. (2011). The everything guide to social media. Massachusetts: Adams media

West, D. M. (2014). Using mobile technology to improve maternal health and fight Ebola: A case study of mobile innovation in Nigeria. Massachusetts: The Brooking Institution.

Wire, K. (2014). Nigeria uses android App and social media to fight Ebola, click health.

World Health Organization. (2015). Ebola situation reports: Cases and deaths data up to May 3, 2015. Retrieved from https://apps.WHO.int/Ebola-situation-reports 


\section{Copyrights}

Copyright for this article is retained by the author(s), with first publication rights granted to the journal.

This is an open-access article distributed under the terms and conditions of the Creative Commons Attribution license (http://creativecommons.org/licenses/by/4.0/). 